\title{
Análise qualitativa das áreas verdes públicas na cidade contemporânea
}

Qualitative analysis of public green areas in the contemporary city

Análisis cualitativo de áreas verdes públicas en la ciudad contemporânea

Sandra Medina Benini Docente do Centro Universitário de Várzea Grande - UNIVAG.

arquiteta.benini@gmail.com

Encarnita Salas Martin

Docente da Faculdade de Ciências e Tecnologia - UNESP campus de Presidente Prudente. encarnita.martin@gmail.com 


\section{INTRODUÇÃO}

No contexto das cidades contemporâneas, particularmente no Brasil, a carência de espaços públicos destinados ao lazer e recreação, assume o debate em diversas áreas do conhecimento. Uma das categorias de tais espaços, as áreas verdes públicas são bem conhecidas pelos benefícios ambientais, tais como: combate à poluição do ar; regulação a umidade e temperatura do ar; contribuição à permeabilidade, fertilidade e umidade do solo, protegendo contra processos erosivos; redução dos níveis de ruído servindo como amortecedor do barulho nas cidades, dentre outros. Em síntese, contribuem para conforto ambiental dos locais onde estão inseridas. Somam-se a estas funções a de embelezamento da cidade, bem como, a função do lazer, onde o homem pode se afastar da cidade de concreto, permitindo que o indivíduo venha a se integrar com a natureza. Para tal, é preciso que as áreas verdes apresentem uma qualidade mínima, para que possa ser atrativa.

Diante da importância do tema, utilizou-se uma metodologia para a análise qualitativa das áreas verdes públicas, tendo como recorte espacial a cidade de Tupã, a qual se justifica pelos aspectos ambientais, como exemplo: a carência de áreas verdes públicas, ausência de equipamentos urbanos que permitam sua apropriação pela população e principalmente, pelo arranjo espacial da cidade ao longo do tempo (1929 a 2007), o que pode ser atribuído à fragilidade jurídica, bem como, à vontade e conveniência políticas dos administradores públicos.

\section{2. ÁREAS VERDES}

Para discorrer sobre o tema, parte-se do pressuposto de que, as áreas verdes urbanas podem ser integradas à categoria de espaços livres na cidade, com características voltadas a recompor os elementos naturais, independente do porte de vegetação (MILANO, 1993). Nesse mesmo sentido, Cavalheiro et al. (1999) afirmam que área verde é "um tipo especial de espaços livres onde o elemento fundamental de composição é a vegetação". Neste mesmo enfoque, Lima et al. (1994, p. 549) tecem uma complementação, em que área verde é uma categoria de espaço livre, desde que haja predominância de vegetação arbórea, a exemplo das "praças, jardins públicos e parques urbanos".

Por sua vez, Nucci (2008, p.120) ao discutir a questão aborda a importância das funções desempenhadas pelos espaços vegetados, ao considerar que, para uma área ser identificada como área verde deve haver a "predominância de áreas plantadas e que deve cumprir três funções (estética, ecológica e lazer)", além de apresentar uma cobertura vegetal e "solo permeável (sem laje) que devem ocupar, pelo menos, $70 \%$ da área".

Independentemente de seu enquadramento quanto à titularidade, sejam as áreas verdes de propriedade pública ou privada, em qualquer das duas categorias devem apresentar algum tipo de vegetação (não somente árvores) com dimensão vertical significativa e é essencial que as mesmas sejam utilizadas com objetivos sociais, ecológicos, científicos ou culturais (NOGUEIRA; WANTUELFER, 2002).

Para tanto, no âmbito desta pesquisa, considera-se área verde pública o conteúdo expresso no conceito, para o qual:

[...] todo espaço livre (área verde / lazer) que foi afetado como de uso comum e que apresente algum tipo de vegetação (espontânea ou plantada), que possa contribuir em termos ambientais (fotossíntese, evapotranspiração, sombreamento, permeabilidade, conservação da 


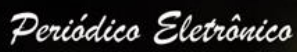

biodiversidade e mitigue os efeitos da poluição sonora e atmosférica) e que também seja utilizado com objetivos sociais, ecológicos, científicos ou culturais. (BENINI, 2009, p. 71).

Como esses espaços são de uso comum do povo, impõem à Administração Municipal, bem como à "coletividade (a sociedade como um todo) o dever de defender e preservar tais espaços (áreas verdes públicas), visto que os mesmos podem contribuir para a sadia qualidade de vida e, consequentemente, para a qualidade ambiental" (BENINI, 2009).

Os estudos elaborados por Nucci $(2008$, p. 109) dão ênfase às condições de conforto propiciadas pelas áreas verdes, onde é comum encontrar-se um ambiente agradável, afastando a "angústia" da cidade, possibilitando ao indivíduo uma interação com a natureza.

Esses ambientes devem ser agradáveis e estéticos, com acomodações e instalações variadas de modo a facilitar a escolha individual. Devem ser livres de monotonia e isentos das dificuldades de espaço e da angústia das aglomerações urbanas. Principalmente para as crianças é fundamental que o espaço livre forneça a possibilidade de experimentar sons, odores, texturas, paladar da natureza; andar descalço pela areia, gramado; ter contato com animais como pássaros, pequenos mamíferos e insetos, etc. (NUCCl, 2008, p. 109)

Gomes (2005, p. 57) complementa a afirmação de Nucci (2008, p. 109), apontando que as áreas verdes, "do ponto de vista psicológico e social, influenciam o estado de ânimo dos indivíduos massificados com o transtorno das grandes cidades". O autor também afirma que a vegetação oferece benefícios ambientais como, por exemplo: combate à poluição do $\operatorname{ar}^{1}$ através da fotossíntese $e^{2}$; "regula a umidade e temperatura do ar; mantém a permeabilidade, fertilidade e umidade do solo e protege-o contra a erosão e; reduz os níveis de ruído servindo como amortecedor do barulho das cidades".

Troppmair e Galina (2003) acrescentam, enfatizando as vantagens das áreas verdes:

a) Criação de microclima mais ameno que exerce função de centro de alta pressão e se reflete de forma marcante sobre a dinâmica da ilha de calor [...];

b) Despoluição do ar de partículas sólidas e gasosas, dependendo do aparelho foliar, rugosidade da casca, porte e idade das espécies arbóreas;

c) Redução da poluição sonora, especialmente por espécies aciculiformes (pinheiros) que podem acusar redução de 6 a 8 decibéis;

d) Purificação do ar pela redução de microorganismos. Foram medidos 50 microorganismos por metro cúbico de ar de mata e até 4.000 .000 por metro cúbico em shopping centers;

e) Redução da intensidade do vento canalizado em avenidas cercadas por prédios;

f) Vegetação como moldura e composição da paisagem junto a monumentos e edificações históricas.

Neste contexto analítico, Loboda e Angelis (2005) afirmam que as áreas verdes urbanas contribuem para a melhoria da qualidade de vida nas cidades. Segundo Gomes (2005, p. 115) as áreas verdes podem proporcionar conforto térmico ${ }^{3}$, visto que essas superfícies verdes interferem na formação de

\footnotetext{
1 “Gases venenosos em suspensão no ar acima da rua e a poeira tóxica cobrem a via carroçável e as calçadas. Automóveis, ônibus e caminhões congestionam as ruas, acelerando e freando, emitindo torrentes de monóxidos de carbono, óxidos de nitrogênio e partículas de chumbo e de combustível não queimado. O pára-e-anda do tráfego, característico de uma rua movimentada, produz mais poluentes do que um tráfego que flui suavemente a uma velocidade constante ao longo de uma rodovia, porque a concentração de fumaça dos escapamentos é maior, numa taxa irregular de combustão. Gotículas de óleo dos motores se transformam num fino aerossol; asbestos desprendem-se dos freios; a pavimentação das ruas literalmente tritura a borracha dos pneus em uma poeira fina" (SPIRN, 1995, p. 71).

2 "A fotossíntese auxilia na umidificação do ar, consequente resfriamento evaporativo" (BARBIRATO; SOUZA; TORRES, 2007, p.113-114).

3 "Conforto térmico - Engloba as componentes termodinâmicas que, em suas relações, se expressam através do calor, ventilação e umidade nos referenciais básicos a esta noção. É um filtro perceptivo bastante significativo, pois afeta a todos
} 


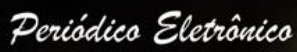

microclimas $^{4}$. Spirn (1995, p. 68-69) explica que as áreas verdes diferem da paisagem de concreto, pela sua capacidade de dispersar a radiação solar, através da evaporação e transpiração.

Na cidade, concreto, pedra, tijolo e asfalto substituem a cobertura vegetal natural do campo. Esses materiais absorvem o calor mais rapidamente e o mantém em maiores quantidades do que as plantas, o solo e a água. [...] Durante o dia todo, o calçamento, as paredes e os telhados absorvem e conservam o calor da irradiação solar. Embora a água e as plantas absorvam também a radiação solar, a maior parte dessa energia é gasta na evaporação e transpiração resultando numa perda de calor maior do que é absorvido. [...] A cidade esfria mais lentamente: ela absorveu mais calor, e a irradiação desse calor para o céu noturno é inibida pelas paredes dos edifícios. (SPIRN, 1995, p. 68-9).

Do mesmo modo, Danni-Oliveira (2003, p. 157) com base nos estudos de climatologia urbana, afirma que as áreas residenciais, através das "trocas dos fluxos de calor e de umidade, bem como a dispersão de poluentes".

Num contexto mais amplo, áreas verdes presentes no tecido urbano, contribuem para os princípios de preservação e conservação e para a sustentabilidade urbana, além de interferirem favoravelmente não apenas na melhoria da qualidade ambiental, mas principalmente na qualidade de vida urbana.

A oferta de espaços públicos é um dos requisitos para a efetivação do direito à cidade, uma vez que esses locais agregam "valores visuais ou paisagísticos, valores recreativos e valores ambientais" no ambiente urbano e que "uma boa qualidade do espaço público pode fornecer a permanência em uma espacialidade tranqüila, o desenvolvimento de atividades sociais e, consequentemente, vitalidade urbana" (BARBIRATO; SOUZA; TORRES, 2007, p.144).

Neste contexto, as áreas verdes públicas, ou seja, jardins ${ }^{5}$ e parques urbanos ${ }^{6}$ vêm "exercer um importante papel na identidade dos lugares, muitas vezes ressaltando as características físicas do sítio" urbano (PISSOL, 2006, p. 2). A implantação de um jardim ou parque urbano contribui para a humanização da cidade.

Os parques e jardins - As mais belas realizações da humanidade são produtos do ideal. Basta recordar os maravilhosos parques, jardins e monumentos sobreviventes de todas as grandes civilizações, para se compreender a força criadora de uma visão de longo alcance, capaz de dar forma e beleza aos elementos mais diversos, a fim de legá-los à posteridade. (LOUREIRO, 1979, p. 24)

A criação, produção e reprodução desses espaços no tempo, agregam valores urbanísticos, essenciais ao arranjo espacial do sítio urbano. Loureiro $(1979$, p. 33$)$ afirma que a cidade deve ser pensada e

permanentemente. Constitui, seja na climatologia médica, seja na tecnologia habitacional, assunto de investigação de importância crescente" (MONTEIRO, 2003, P. 2 4). "A sensação de conforto térmico está associada com o ritmo de troca de calor entre o corpo e o meio ambiente, sendo assim, o desempenho humano durante qualquer atividade pode ser otimizado, desde que o ambiente propicie condições de conforto e que sejam evitadas sensações desagradáveis, tais como: dificuldade de eliminar o excesso de calor produzido pelo organismo; perda exagerada de calor pelo corpo e desigualdade de temperatura entre as diversas partes do corpo" (BARBIRATO; SOUZA; TORRES, 2007, p.144).

4 "Cada cidade é composta por um mosaico de microclimas radicalmente diferentes, os quais são criados pelos mesmos processos que operam na escala geral da cidade. Os mesmos fenômenos que caracterizam o mesoclima urbano existem em miniatura por toda a cidade - pequenas ilhas de calor, microinversões, bolsões de grave poluição atmosférica e diferenças locais no comportamento dos ventos" (SPIRN, 1995, p. 71).

${ }^{5}$ Um jardim público compreende aqueles cuja manutenção fica ao encargo dos poderes públicos e se destinam ao uso e gozo da população em geral, com as limitações necessárias a sua função [...] (NIEMEYER, 2005, p.10).

${ }^{6}$ "Considera como parque todo espaço de uso público destinado à recreação de massa, qualquer que seja o seu tipo, capaz de incorporar intenções de conservação e cuja estrutura morfológica é auto-suficiente, isto é, não é diretamente influenciada em sua configuração por nenhuma estrutura construída em seu entorno" (MACEDO; SAKATA, 2002, p. 14). 


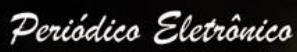

produzida, considerando as áreas verdes púbicas como requisito básico à qualidade urbana. Para Robba e Macedo (2003, p. 44-45), essa qualidade urbana, está implícita nos valores ambientais, funcionais, estéticos e simbólicos dessas áreas.

\section{ESTUDO DE CASO}

A Estância Turística de Tupã está localizada a oeste do Estado de São Paulo, tendo como limites territoriais uma área de $628,5 \mathrm{~km}^{2}$, que abrange os Distritos de Varpa, Distrito de Universo, Distrito de Parnaso e a cidade de Tupã. O Município faz divisa com Arco-Íris, Herculândia, Quintana, Quatá, Bastos, João Ramalho e lacri (Figura 1).

Figura 1 - Localização do Município de Tupã/SP.

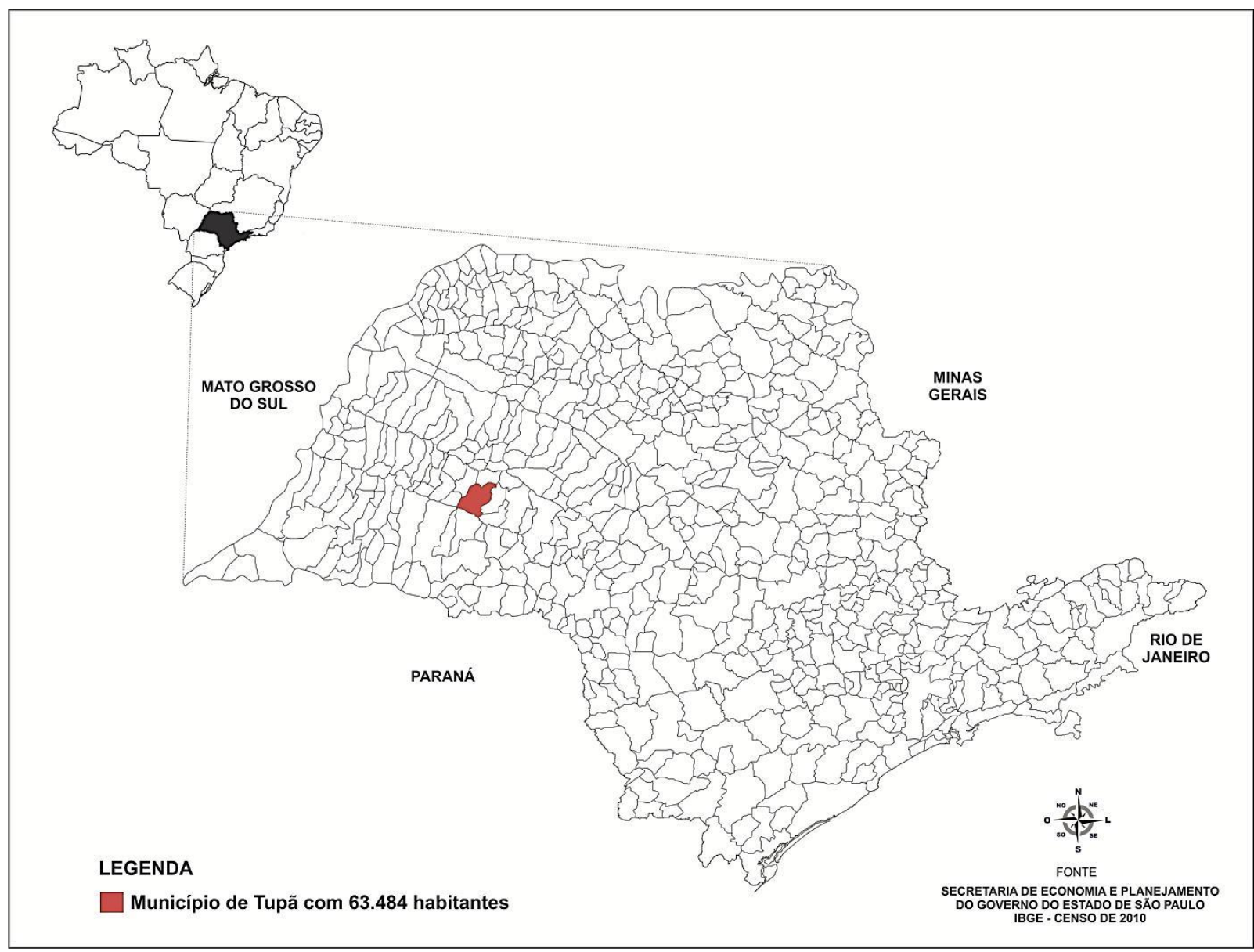

Fonte: BENINI, 2015

No que se refere ao processo de urbanização, este não deve ser considerado como "mera modificação dos padrões demográficos e espaciais", pois envolve, "com efeito o conjunto dos modos de produção e consumo, a emergência e generalização de novos valores e instituições, a implantação de redes de transporte e comunicação" (VAINER; SMOLKA, 1995, p 19).

A cidade de Tupã, como a maioria das cidades do Estado de São Paulo, teve em sua fase inicial de urbanização orientada por uma morfologia caracterizada por quadrícula ou modelo nominado por tabuleiro de xadrez ${ }^{7}$.

7 Segundo Ferrari (1977), o sistema ou estrutura ortogonal consiste de ruas que se cruzam em ângulo reto formando quadrados (tabuleiro xadrez) ou retângulo (grelhas ou grades). 
A expansão urbana deste sítio foi marcada por novos traçados, a exemplo do linear, que permitia a composição de uma densidade mais uniforme, circulação fácil (FERRARI, 1977). Esse processo de expansão foi ressaltado pela ocupação dos fundos de vales e por áreas periféricas na malha urbana, resultado da intervenção de diferentes agentes sociais (usuário e loteador) e o Estado (Figura 2).

Figura 2 - Crescimento Urbano da Cidade de Tupã

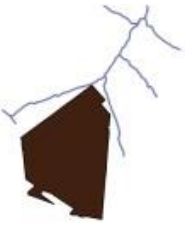

Sede - 1929

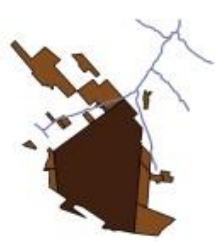

Década de 40

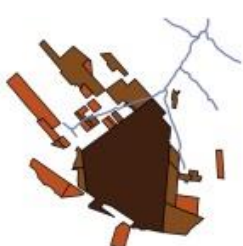

Década de 50

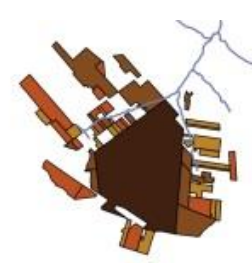

Década de 60

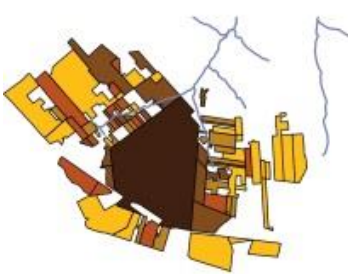

Década de 70

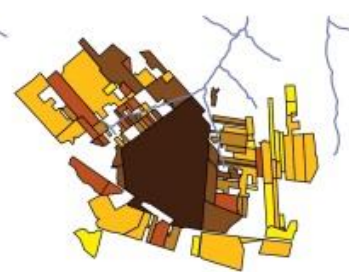

Década de 80

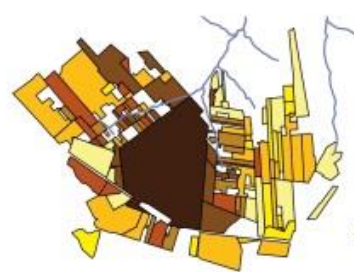

Década de 90
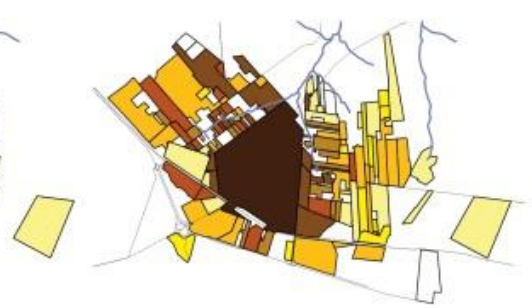

A partir de 2000
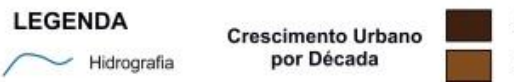

Sede - 1929 Década de 40

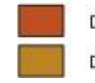

Década de 50 Década de 60

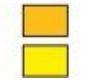

Década de 70 Década de 80 Após 2.000

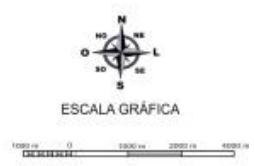

Fonte: Adaptado de Benini, 2009

Esse crescimento da malha urbana gerou vários problemas socioambientais, como por exemplo: a carência de equipamentos urbanos (escolas, creches, postos de saúde, espaços de lazer e recreação, entre outros) e de infraestrutura (pavimentação, galerias de água, esgoto e drenagem de águas pluviais, iluminação pública, entre outros). Entretanto, é possível observar que estes não atingem toda a malha urbana localizando-se, principalmente, nas áreas mais baixas da cidade onde, normalmente estão instalados bairros de nível socioeconômico mais baixo. Em geral, as classes sociais (média e alta) residem em áreas de relevo mais elevado, com boa infraestrutura urbana e social, enquanto a população de menor renda ocupa tanto áreas periféricas, com desvalorização imobiliária, como aquelas nas proximidades dos leitos de córregos urbanos que estão sujeitas a inundações e com carência de infraestrutura e de espaços públicos de convivência comunitária.

\section{RESULTADOS}

A pesquisa constatou que desde o período da fundação do núcleo urbano da cidade de Tupã até o ano de 2009, o percentual de áreas verdes públicas (PVAP) destinado e afetado (praças e jardins) nos loteamentos e bairros, foi de 3,71\%. Destaca-se que, por decisões políticas e administrativas das 


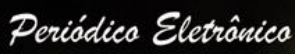

gestões anteriores, parte destes espaços foram desafetados ${ }^{8}$ e doados para implantação de templos religiosos, associações, prestadoras de serviços e inclusive, para instalação de empreendimentos comerciais.

No cenário atual, após o processo de desafetação desses espaços, o PVAP passou a ser de 2,26\%, o que indica que a cidade apresenta uma perda real de $1 / 3$ de suas áreas verdes públicas. A pesquisa verificou que desse $2 / 3$ restante, somente uma pequena parcela exerce suas funções ambientais, culturais, de lazer, etc.

Na figura 3 (Evolução do Percentual de Áreas Verdes Públicas da Cidade de Tupã/SP) é possível acompanhar a variação do percentual de áreas verdes públicas ao longo do tempo.

Figura 3 - Evolução do Percentual de Áreas Verdes Públicas

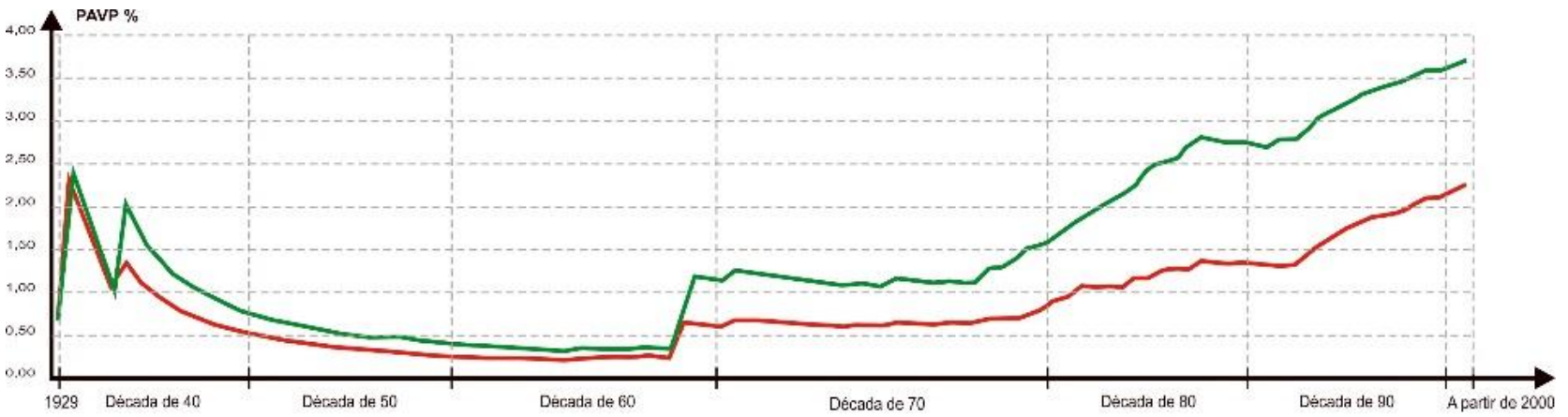

LEGENDA

PAVP Aprovado

Percentual de áreas verdes públicas da cidade de Tupã que foram afetadas como de uso comum no a toda aprovação dos loteamentos $=3,71 \%$

PAVP Atual

Percentual de áreas verdes públicas atuais da cidade de Tupã que permanecem afetadas como de uso comum $=2,26 \%$ Fonte: Adaptado de Benini, 2009

O PVAP apresentado na figura 03 interfere diretamente no Índice de Área Verde (IAV), o qual tem sua base de cálculo na disponibilidade de áreas verdes para cada habitante do espaço urbano. Segundo Troppmair e Galina (2003), a ONU (Organização das Nações Unidas) recomenda que seja adotado "12 metros quadrados de área verde por habitante para que haja equilíbrio entre a quantidade de oxigênio e gás carbônico".

Para aferir o IAV na cidade de Tupã, a pesquisa empírica considerou áreas verdes do município, partindo da análise espacial dos loteamentos, tendo sido verificados os seguintes valores:

- Índice de Área Verde Pública Aprovada ${ }^{9}=28,00 \mathrm{~m}^{2} / \mathrm{hab}$

- Índice de Área Verde Pública Atual ${ }^{10}=11,99 \mathrm{~m}^{2} / \mathrm{hab}$

- Índice de Área Verde Pública Urbanizada ${ }^{11}=1,64 \mathrm{~m}^{2} /$ hab (Figura 04)

\footnotetext{
${ }^{8} \mathrm{~A}$ desafetação é o ato administrativo que pode ser expresso ou tácito, que retira do bem a finalidade originária, como por exemplo, uma área verde pública que foi afetada como "uso comum" e por meio da desafetação passa integrar os "bens dominiciais" do Município, permitindo ao Administrador Público dispor deste espaço para qualquer outro fim (PIRES, 2006, p.61).

9 Índice de Área Verde Pública Aprovada é a razão entre todas as áreas verdes públicas (que foram afetadas como de uso comum no ato do registro dos loteamentos da cidade de Tupã) e a população (Censo Municipal de 2007) de cada loteamento (BENINI, 2019).

${ }^{10}$ Índice de Área Verde Pública Atual é obtido do quociente entre todas as áreas verdes públicas que permaneceram afetadas como de uso comum dos loteamentos da cidade de Tupã e a população (Censo Municipal de 2007) de cada loteamento (BENINI, 2019).
} 


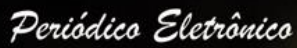 Fórum Amblenta

Figura 04 - Índice de Área Verde Pública Urbanizada na cidade de Tupã

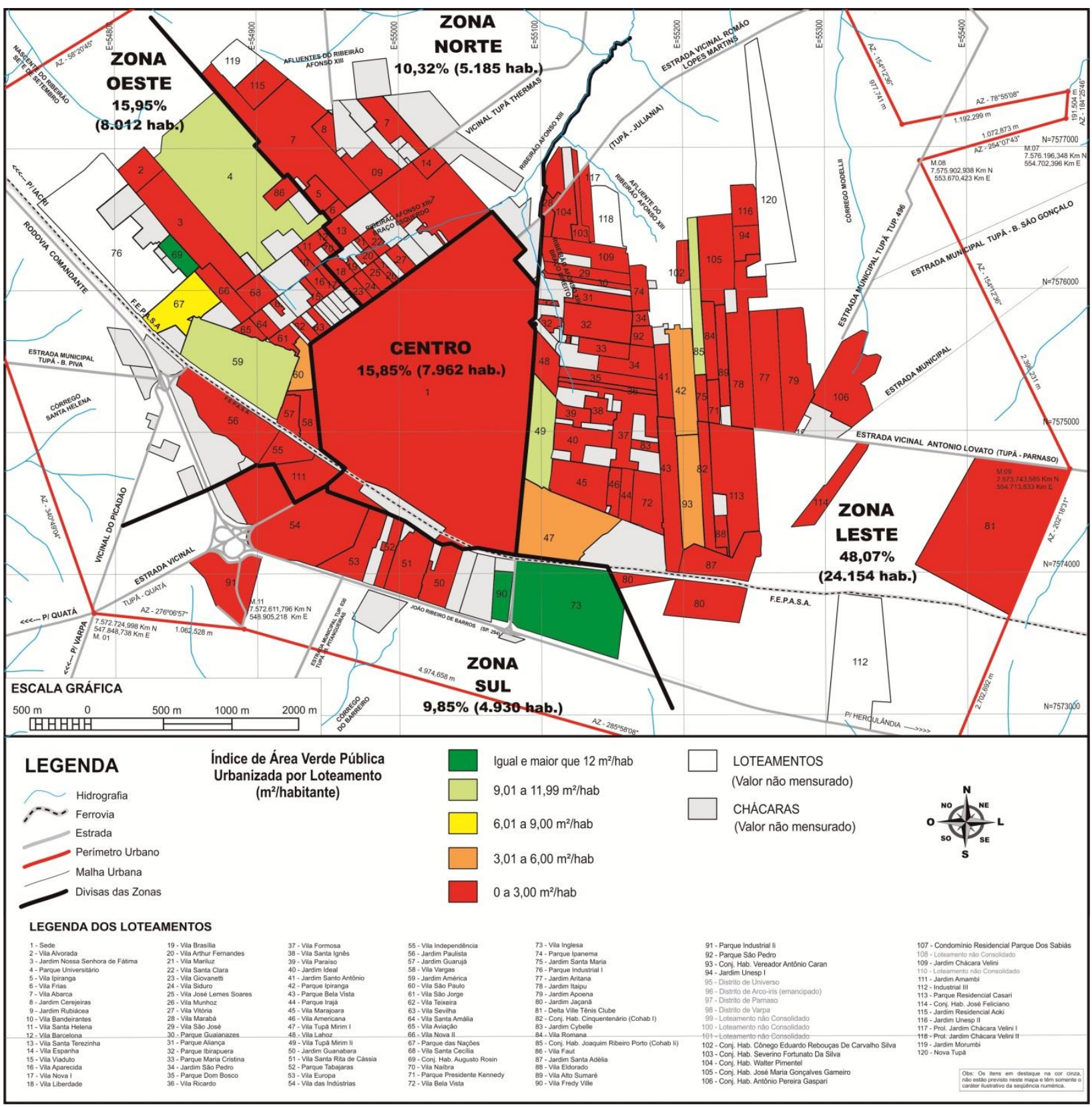

Fonte: Adaptado de Benini, 2009

Para verificar a qualidade das Áreas Verdes Públicas Urbanizadas, na cidade de Tupã, foi realizado um levantamento dos equipamentos e atributos existentes (Quadro 1).

\footnotetext{
${ }^{11}$ Índice de Área Verde Pública Urbanizada considerou todas as áreas verdes públicas que permaneceram afetadas como de uso comum e têm instalados equipamentos e mobiliários, nos loteamentos da cidade de Tupã e dividiu-se pela população (BENINI, 2019).
} 


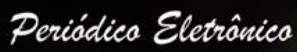

Quadro 1 - Descrição dos Equipamentos e Atributos Analisados das Áreas Verdes Públicas Urbanizada da Cidade de Tupã/SP

\begin{tabular}{|c|c|c|}
\hline ATRIBUTOS & VARIÁVEIS & DESCRIÇÃO / PROCEDIMENTOS \\
\hline \multirow{8}{*}{ Identificação } & Cód. & Código de identificação para orientação deste trabalho \\
\hline & Denominação & Denominação atribuída pela Administração Pública \\
\hline & Setor & $\begin{array}{l}\text { Divisão por setores determinado pela SEPLIN (Centro, Zona Norte, Zona Sul, Zona } \\
\text { Leste, Zona Oeste) }\end{array}$ \\
\hline & № Lt. & Número do loteamento segundo cadastro da SEPLIN \\
\hline & Loteamento & Denominação dos loteamentos segundo da Administração Pública. \\
\hline & Área (m2) & Área em metros quadrados. \\
\hline & Ato Oficial & $\begin{array}{l}\text { Atos Oficiais da Administração Pública (decreto ou lei municipal) que atribuíram à } \\
\text { dominação e função ao local. }\end{array}$ \\
\hline & Data Ato & Datas dos Atos Oficiais \\
\hline \multirow{3}{*}{ Caracterização } & Entorno & $\begin{array}{l}\text { Identificação do entorno das áreas verdes públicas: } \mathrm{C} \text { - comércio; I - indústria; O - } \\
\text { outros; R - residências; e, TV - terrenos vagos. }\end{array}$ \\
\hline & Forma & $\begin{array}{l}\text { As formas geométricas das áreas verdes públicas: } \mathrm{C} \text { - circular; I - irregular; } \mathrm{Q}- \\
\text { quadrada; } \mathrm{R} \text { - retangular; e, } \mathrm{T} \text { - triangular. }\end{array}$ \\
\hline & Edificação & $\begin{array}{l}\text { Verificação da existência de edificações nas áreas verdes públicas: } \mathrm{C} \text { - cultural; I - } \\
\text { institucional; } \mathrm{R} \text { - religiosa; e, } \mathrm{O} \text { - outras. }\end{array}$ \\
\hline \multirow{2}{*}{ Acessibilidade } & Circulação & $\begin{array}{l}\text { Verificação da existência de circulação que permitam a mobilidade de usuários em } \\
\text { qualquer condição física }\end{array}$ \\
\hline & Tipo de Pavimentação & $\begin{array}{l}\text { Classificação dos tipos de pavimentação das áreas verdes públicas: C - Concreto; B } \\
\text { - Bloquete; P - Paralelepípedo; e, PP - Petit Pavê. }\end{array}$ \\
\hline \multirow{3}{*}{ Vegetação } & Flora & Verificação da existência de espécies vegetais e arbóreas. \\
\hline & Paisagismo & Verificação da existência de arranjo e composição do vegetação. \\
\hline & Permeabilidade (\%) & Levantamento da taxa de permeabilidade \\
\hline \multirow{6}{*}{ Mobiliário } & Banco & Quantidade de bancos. \\
\hline & Tipo de Banco & $\begin{array}{l}\text { Classificação dos tipos de bancos das áreas verdes públicas: A - Alvenaria; C - } \\
\text { Concreto; e, M - Madeira. }\end{array}$ \\
\hline & Bebedor & Verificação da existência de bebedor para os usuários do espaço. \\
\hline & Iluminação Baixa & Quantidade de luminárias baixas \\
\hline & Iluminação Alta & Quantidade de luminárias altas \\
\hline & Lixeira & Quantidade de lixeiras \\
\hline \multirow{8}{*}{$\begin{array}{l}\text { Outros } \\
\text { Mobiliários }\end{array}$} & Ponto de Ônibus & Verificação da existência de ponto de ônibus \\
\hline & Ponto de Táxi & Verificação da existência de ponto de táxi \\
\hline & Banca de Revista & Verificação da existência de banca de revista \\
\hline & Telefone Público & Verificação da existência de telefone público \\
\hline & Quiosque & Verificação da existência de quiosque \\
\hline & Mesa de Jogo & Verificação da existência de mesa de jogo \\
\hline & Sanitário & Verificação da existência de sanitários \\
\hline & Estacionamento & Verificação da existência de estacionamento \\
\hline \multirow{4}{*}{ Recreação } & $\begin{array}{l}\text { Equipamentos de } \\
\text { Exercícios }\end{array}$ & Verificação da existência de equipamentos para exercícios \\
\hline & $\begin{array}{l}\text { Equipamentos para } \\
\text { Terceira Idade }\end{array}$ & $\begin{array}{l}\text { Verificação da existência de equipamentos para a terceira idade, como por } \\
\text { exemplo: academia da terceira idade }\end{array}$ \\
\hline & Parque Infantil & Verificação da existência de parque infantil \\
\hline & Quadra Esportiva & Verificação da existência de quadra esportiva \\
\hline \multirow{3}{*}{ Cultural } & Palco & Verificação da existência de palco \\
\hline & Obra de Arte & Verificação da existência de obras de arte \\
\hline & $\begin{array}{l}\text { Chafariz / Espelho de } \\
\text { Água }\end{array}$ & Verificação da existência de chafariz / espelho de água \\
\hline \multirow{2}{*}{$\begin{array}{l}\text { Serviços } \\
\text { Públicos }\end{array}$} & Conservação e Limpeza & Verificação da existência de disponibilidade de serviços de conservação e limpeza \\
\hline & Segurança & Verificação da existência de presença de segurança no local \\
\hline
\end{tabular}

Fonte: Angelis (2004, p. 61) adaptado Benini, 2009.

O desenvolvimento da metodologia para elaboração do arranjo de atributos do Quadro 01, foi baseado nos estudos de Angelis (2004), objetivando sistematizar a coleta de dados para obtenção do produto final. 
Os resultados obtidos pela análise quantitativa das áreas verdes públicas demonstraram a carência na diversidade de equipamentos e mobiliários públicos destes espaços.

Com base nos dados coletados foi possível organizar propor uma análise qualitativa desses espaços, utilizando Quadro 02 - Atribuição de peso (valor) aos atributos das Áreas Verdes Públicas.

\begin{tabular}{|c|c|c|c|}
\hline ATRIBUTOS & \multicolumn{2}{|c|}{ VARIÁVEIS } & PESO \\
\hline Acessibilidade & \multicolumn{2}{|l|}{ Circulação } & 3 \\
\hline \multirow{5}{*}{ Vegetação } & \multicolumn{2}{|l|}{ Flora } & 3 \\
\hline & \multirow{4}{*}{ Permeabilidade (\%) } & superior a $75 \%$ & 3 \\
\hline & & de 50 a $75 \%$ & 2 \\
\hline & & de 25 a $49 \%$ & 1 \\
\hline & & inferior a $25 \%$ & 0 \\
\hline \multirow{4}{*}{ Mobiliário } & \multicolumn{2}{|l|}{ Banco } & 3 \\
\hline & \multicolumn{2}{|l|}{ Bebedor } & 3 \\
\hline & \multicolumn{2}{|l|}{ Iluminação } & 3 \\
\hline & \multicolumn{2}{|l|}{ Lixeira } & 3 \\
\hline \multirow{8}{*}{$\begin{array}{l}\text { Outros } \\
\text { Mobiliários }\end{array}$} & \multicolumn{2}{|l|}{ Ponto de Ônibus } & 1 \\
\hline & \multicolumn{2}{|l|}{ Ponto de Táxi } & 1 \\
\hline & \multicolumn{2}{|l|}{ Banca de Revista } & 1 \\
\hline & \multicolumn{2}{|l|}{ Telefone público } & 1 \\
\hline & \multicolumn{2}{|l|}{ Quiosque } & 1 \\
\hline & \multicolumn{2}{|l|}{ Mesa de Jogo } & 1 \\
\hline & \multicolumn{2}{|l|}{ Sanitário } & 1 \\
\hline & \multicolumn{2}{|l|}{ Estacionamento } & 1 \\
\hline \multirow{4}{*}{ Recreação } & \multicolumn{2}{|c|}{ Equipamentos para Exercícios } & 3 \\
\hline & \multicolumn{2}{|c|}{ Equipamentos para Terceira Idade } & 3 \\
\hline & \multicolumn{2}{|l|}{ Parque Infantil } & 3 \\
\hline & \multicolumn{2}{|l|}{ Quadra Esportiva } & 3 \\
\hline \multirow{3}{*}{ Cultural } & \multicolumn{2}{|l|}{ Palco } & 2 \\
\hline & \multicolumn{2}{|l|}{ Obra de Arte } & 2 \\
\hline & \multicolumn{2}{|c|}{ Chafariz / Espelho de Água } & 2 \\
\hline \multirow{2}{*}{$\begin{array}{l}\text { Serviços } \\
\text { Públicos }\end{array}$} & \multicolumn{2}{|c|}{ Conservação e Limpeza } & 3 \\
\hline & \multicolumn{2}{|l|}{ Segurança } & 3 \\
\hline
\end{tabular}

Fonte: Angelis (2004, p. 61) adaptado por Benini, 2009.

A atribuição de peso (valor) foi feita a partir do levantamento de todas as variáveis presentes nas áreas verdes públicas de Tupã, com o objetivo de organizar grupos segundo suas características e finalidade. Cada agrupamento foi considerado como atributo e recebeu um peso (valor) que variou de 0 a 3 , considerando a função e necessidade dos usuários destes espaços.

A partir da realização do levantamento qualitativo das áreas verdes públicas da cidade de Tupã/SP foi possível produzir a Figura 4 - Avaliação Qualitativa das Áreas Verdes Públicas Urbanizadas, com objetivo de nortear as futuras políticas públicas e intervenções urbanísticas. 


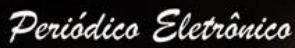 Fórum Amblental

Figura 04 - Avaliação Qualitativa das Áreas Verdes Públicas Urbanizadas

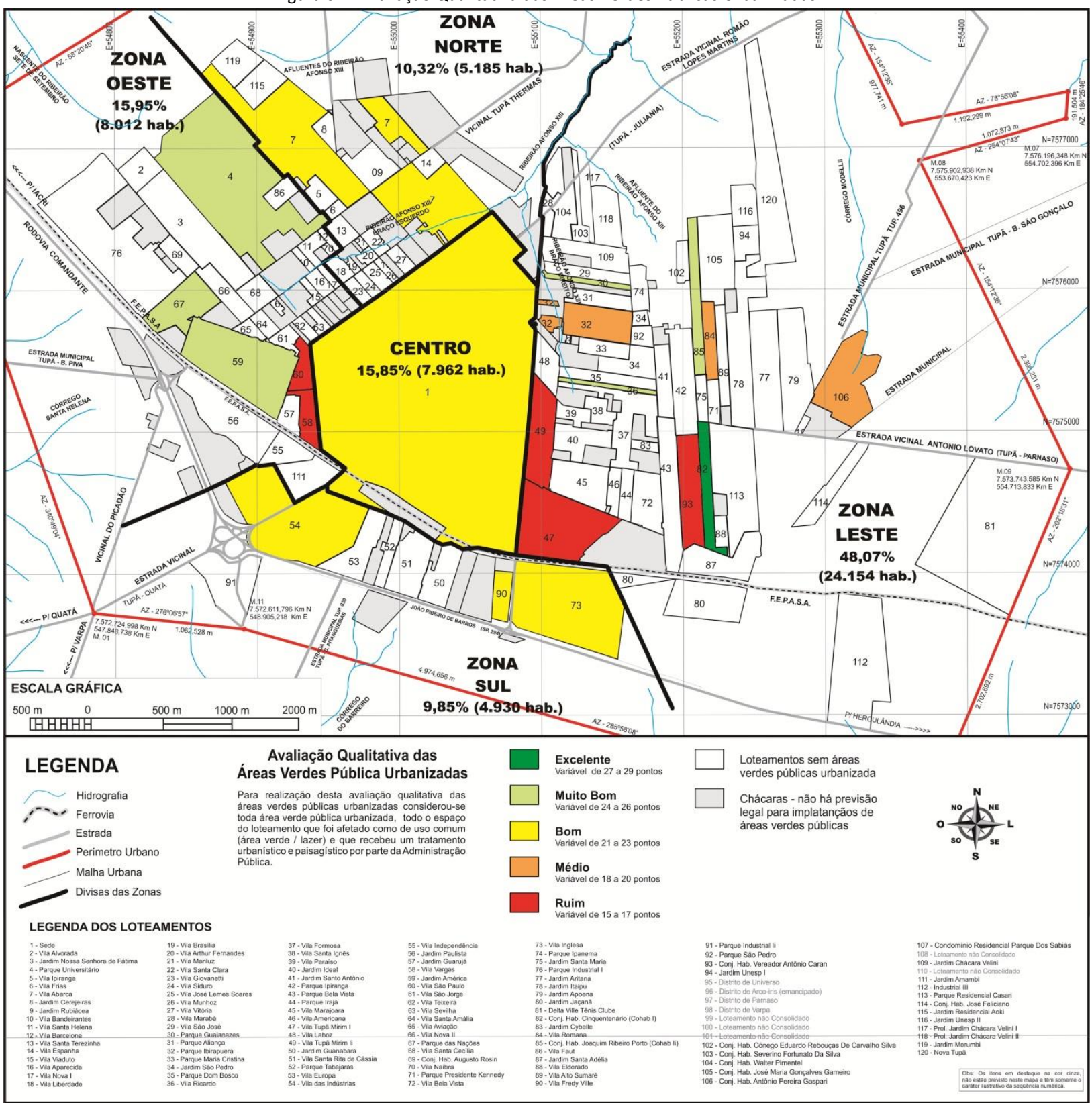

Fonte: Adaptado de Benini, 2009

Na Tabela 01 - Síntese da Avaliação Qualitativa das Áreas Verdes Públicas Urbanizadas foi possível comparar o Índice de Áreas Verdes Públicas com o resultado da avaliação qualidade desses espaços. Do resultado obtido, destaca-se o Conjunto Habitacional Cinquentenário, localizado na Zona Leste, que foi classificado como excelente. Entretanto, o Índice de áreas Verdes Públicas é muito baixo, 2,95 m2 por habitante. 


\section{Periódica Eletrânica}

Tabela 01 - Síntese da Avaliação Qualitativa das Áreas Verdes Públicas Urbanizadas

\begin{tabular}{|c|c|c|c|c|c|}
\hline \multirow[b]{2}{*}{ № DE CAD. } & \multirow[b]{2}{*}{ QUALIFICAÇÃO } & \multirow[b]{2}{*}{ LOTEAMENTO } & \multirow[b]{2}{*}{ SETOR } & \multicolumn{2}{|c|}{ ÁREAS VERDES PÚBLICAS } \\
\hline & & & & ÍNDICE (m²/hab) & $\begin{array}{l}\text { QUALIDADE } \\
\text { (peso/valor) }\end{array}$ \\
\hline 1 & & SEDE & CENTRO & 2,17 & Bom \\
\hline 4 & Parque & Universitário & OESTE & 10,48 & Muito Bom \\
\hline 7 & Vila & Abarca & NORTE & 1,66 & Bom \\
\hline 30 & Parque & Guaianazes & LESTE & 1,49 & Muito Bom \\
\hline 32 & Parque & Ibirapuera & LESTE & 0,61 & Médio \\
\hline 36 & Vila & Ricardo & LESTE & 2,03 & Muito Bom \\
\hline 47 & Vila & Tupã Mirim I & LESTE & 3,03 & Ruim \\
\hline 49 & Vila & Tupã Mirim II & LESTE & 9,22 & Ruim \\
\hline 54 & Vila & Das Indústrias & SUL & 0,13 & Bom \\
\hline 58 & Vila & Vargas & OESTE & 0,33 & Ruim \\
\hline 59 & Jardim & América & OESTE & 9,62 & Muito Bom \\
\hline 60 & Vila & São Paulo & OESTE & 4,95 & Ruim \\
\hline 69 & Núcleo Hab. & Augusto Rosin & OESTE & 25,72 & Muito Bom \\
\hline 73 & Vila & Inglesa & SUL & 18,41 & Bom \\
\hline 82 & Conj. Hab. & Cinquentenário & LESTE & 2,95 & Excelente \\
\hline 84 & Vila & Romana & LESTE & 1,02 & Médio \\
\hline 85 & Conj. Hab. & Joaquim Ribeiro Porto & LESTE & 11,39 & Muito Bom \\
\hline 90 & Vila & Fredy Ville & SUL & 31,66 & Bom \\
\hline 93 & Conj. Hab. & Antônio Caran & LESTE & 4,62 & Ruim \\
\hline 106 & Conj. Hab. & $\begin{array}{c}\text { Antônio Pereira } \\
\text { Gaspar }\end{array}$ & LESTE & 0,25 & Médio \\
\hline
\end{tabular}

A pesquisa constatou que dos 111 loteamentos implantados na cidade de Tupã, somente 20 destes tem Áreas Verdes Públicas Urbanizadas, o que representa um percentual de $18,01 \%$, ou seja, as áreas não são de fato implantadas. Do total de $20,75 \%$ das Áreas Verdes Públicas Urbanizadas dos loteamentos avaliados obtiveram um resultado positivo na avaliação, enquanto que $25 \%$ desses espaços foram classificados como ruins, o que sinaliza a necessidade de uma intervenção imediata nesses locais.

\section{CONCLUSÕES}

As áreas de uso público, especificamente aquelas afetadas como áreas verdes, integrantes do patrimônio público municipal, são dotadas de funções especiais de diversas dimensões a serem cumpridas no espaço urbano. Como equipamento público, as áreas verdes públicas são elementos estruturantes da paisagem urbana que devem ofertar lazer e recreação para a população, além de colaborar para melhoria da qualidade ambiental urbana.

A cidade de Tupã deveria apresentar um IAVP dos loteamentos aprovado de $28,00 \mathrm{~m}^{2} / \mathrm{hab}$, entretanto, durante o processo de urbanização houve uma perda real de $16,02 \mathrm{~m}^{2} /$ hab desses espaços por conjunturas políticas da administração municipal. O IAVP atual da cidade é de $11,99 \mathrm{~m}^{2} / \mathrm{hab}$. Entretanto, deste valor somente 1,64 $\mathrm{m}^{2} / \mathrm{hab}$ foram urbanizados e compõem o patrimônio paisagístico da cidade com 34 jardins. Estes números demonstram a necessidade iminente de serem implantados novos jardins e/ou bosques e/ou parques, para corrigir este déficit de 10,35 $\mathrm{m}^{2} /$ hab de Áreas Verdes Públicas Urbanizadas.

A metodologia utilizada permite que se avalie o Índice de Áreas Verdes (IAV) e a qualidade das Áreas Verdes Públicas Urbanizadas, ou seja, se há área verde suficiente por habitante e a qualidade de tais espaços. Observou-se que em Tupã além do IAV não atingir o recomendado pela ONU, a qualidade áreas também não apresenta uma boa qualidade.

Tal situação demonstra a necessidade clara e urgente de que sejam elaboradas políticas públicas que tenham como objetivo o respeito e a implantação, de fato, das áreas afetadas como áreas verdes. E 
também que as Áreas Verdes Públicas Urbanizadas, apresentem qualidade para que cumpram seu objetivo de área de lazer e recreação, além de sua importância para a qualidade ambiental urbana.

\section{REFERÊNCIAS}

BARBIRATO, Gianna Melo; SOUZA, Léa Cristina Lucas de; TORRES, Simone Carnaúba. Clima e Cidade: a abordagem climática como subsídio para estudos urbanos. Maceió: EDUFAL, 2007, 164 p.

BENINI, Sandra Medina. Áreas Verdes Públicas: A construção do conceito e a análise geográfica desses espaços no ambiente urbano. Presidente Prudente: 2009. Dissertação (mestrado) - Universidade Estadual Paulista, Faculdade de Ciências e Tecnologia, 2009.

BENINI, Sandra Medina. Infraestrutura verde como prática sustentável para subsidiar a elaboração de planos de drenagem urbana: estudo de caso da cidade de Tupã/SP. Tese (doutorado) - Universidade Estadual Paulista, Faculdade de Ciências e Tecnologia. Presidente Prudente, 2015.

CAVALHEIRO, Felisberto et al. Proposição de terminologia para o verde urbano. Boletim Informativo Sociedade Brasileira de Arborização Urbana, Rio de Janeiro: SBAU, ano VII, n.3, p.7, jul./ago./set. 1999. Disponível em: <http://www.geografia.ufpr.br/laboratorios/labs/arquivos/CAVALHEIRO\%20et\%20al\%20(1999).pdf> Acesso em: 19 jan. 2009.

DANNI-OLIVEIRA, Inês Moresco. A cidade de Curitiba e a Poluição do ar: Implicações de seus atributos urbanos e geoecológicos na dispersão de poluentes em período de inverno. In: MONTEIRO, Carlos Augusto de Figueiredo; MENDOÇA, Francisco (Org.). Clima Urbano. São Paulo: Contexto, 2003, p.155-172.

FERRARI, Celson. Dicionário de Urbanismo. 1. ed. São Paulo: Disal, 2004.

GOMES, Marcos Antônio Silvestre. As praças de Ribeirão Preto-SP: uma contribuição geográfica ao planejamento e à gestão dos espaços públicos. 204 f. 2005. Dissertação (Mestrado) Universidade Federal de Uberlândia, Programa de Pós-Graduação em Geografia. Uberlândia, 2005.

LIMA, Ana Maria Liner Pereira et al. Problemas de utilização na conceituação de termos como espaços livres, áreas verdes e correlatos. In. 2o Congresso Brasileiro Sobre Arborização Urbana, 1994, ANAIS... São Luís. p. 539550. Disponível em: <http://www.geografia.ufpr.br/laboratorios/labs/arquivos/LIMA\%20et\%20al\%20(1994).pdf>. Acesso em: 10 jul. 2008

LOBODA, Carlos Roberto; ANGELIS, Bruno Luiz Domingos de. Áreas Públicas Urbanas: conceito, uso e funções. Ambiência. Guarapuava, PR, v.1 n.1, p. 125-139, jan./jun. 2005, ISSN 1808 - 0251. Disponível em: <http://www.unicentro.br/editora/revistas/ambiencia/v1n1/artigo\%20125-139_.pdf>. Acesso em: 06 jul. 2008.

LOUREIRO, Maria Amélia Salgado. A cidade e as áreas verdes. São Paulo: Secretaria de Serviços e Obras do Município, 1979, 185 p.

MACEDO, Silvio Soares; SAKATA, Francine Gramacho. Parques Urbanos no Brasil. São Paulo: Edusp, Impressa Oficial do Estado, 2002. 208 p.

MILANO, M. S.. Planejamento da arborização urbana: relação entre áreas verdes e ruas arborizadas. In: Encontro Brasileiro sobre Arborização Urbana, 4, 1990. Curitiba. Anais... Curitiba: Sociedade Braisleira de Arborização Urbana, 1990.

MONTEIRO, Carlos Augusto de Figueiredo. Teoria do clima urbano: Um projeto e seus caminhos. In: MONTEIRO, Carlos Augusto de Figueiredo; MENDOÇA, Francisco (Org.). Clima Urbano. São Paulo: Contexto, 2003 , p. 9 -67.

NIEMEYER, Carlos Augusto da Costa. Paisagismo no planejamento arquitetônico. Uberlândia: EDUFU, 2005, 127 p.

NOGUEIRA, A.; WANTUELFER, G.. Florestas Urbanas: planejamento para melhoria da qualidade de vida. Viçosa: Aprenda Fácil, 2002.

$\mathrm{NUCCl}$, João Carlos. Qualidade ambiental e adensamento urbano: um estudo de ecologia e planejamento da paisagem aplicado ao distrito de Santa Cecília (MSP). 2a ed. Curitiba: O Autor, 2008. 150 p. Disponível em: < 
http://www.geografia.ufpr.br/laboratorios/labs/arquivos/qldade_amb_aden_urbano.pdf>Acesso em: 24 fev. 2008.

PIRES, Luis Manuel Fonseca. Loteamentos Urbanos: natureza jurídica. São Paulo: Quartier Latin, 2006,160 p.

PISSOL, Kátia Maria Santos de Andrade. A Dinâmica Urbana: Uma Leitura da Cidade e da Qualidade de Vida no Urbano. Caminhos de Geografia, Uberlândia - MG, v. 7, n. 17, p. 1-7, fev. 2006, ISSN: 1678-6343. Disponível em: <http://www.caminhosdegeografia.ig.ufu.br/viewarticle.php?id=25\&layout=abstract> Acesso em: 10 jan. 2009.

ROBBA, F; MACEDO, S. S.. Praças brasileiras: public squares in Brazil. São Paulo: Edusp: Imprensa oficial do Estado. 2002, 312p.

SPIRN, Anne Whiston. O Jardim de Granito: A natureza no desenho da cidade. Tradução Paulo Renato Mesquita Pellegrino. São Paulo: Edusp, 1995. 345 p.

TROPPMAIR, Helmut; GALINA, Márcia Helena. Áreas verdes. Território \& Cidadania. Rio Claro, SP, ano III, no 2, jun-dez, 2003. Disponível em:

<http://www.rc.unesp.br/igce/planejamento/territorioecidadania/Artigos/helmut\%201.htm> Acesso em: 21 mai. 2008.

VAINER, C. B.; SMOLKA, M. O. Em tempos de liberalismo: tendências e desafios do planejamento urbano no Brasil in: PIQUET, R.; RIBEIRO, A. C. T. Brasil, território da desigualdade: descaminhos da modernização. Rio de Janeiro: Jorge Zahar (editor) e Fundação Universitária José Bonifácio, 1995. 